\title{
THE PROBLEM OF CHOOSING ANESTHESIA METHOD FOR SURGICAL INTERVENTIONS ON THE LOWER LIMBS IN YOUNG PATIENTS
}

\author{
Marine Georgiyants, Olexii Popsuishapka, Victor Ryndenko, Sergiy Kursov, \\ Volodymyr Babalian, Nataliia Bohuslavska
}

The relevance of the topic is due to the prevalence of lower limbs injuries in people of working age, the complexity of the methods of their surgical treatment and the problem of finding the optimal method of anesthesia in terms of efficiency and safety.

Objective of the study: to conduct a systematic analysis of modern scientific literature data on the possibility of using anesthesia methods during surgical interventions and in the case of anesthesia for injuries of the lower limbs in people of working age.

Materials and methods. A search for scientific sources was carried out in the scientometric databases Scopus and Web of Science, Google Scholar, archives of journals using the keywords "general anesthesia", "regional anesthesia", "injuries of the lower limbs", "young people", "general anesthesia". The search depth was 8 years.

Conclusions. The problem of choosing the method of anesthesia during traumatological surgeries in people of working age has no final solution. In general, both general and regional anesthesia can be used, despite their advantages and the possibility of complications in each case. However, in clinical practice over the past decade, general anesthesia is not always the best method of pain relief. But regional methods have less effect on the vital functions of the body, and the use of ultrasound navigation and modern local anesthetics in a minimum sufficient amount makes anesthesia conduction more effective and safe. The disadvantages of regional anesthesia can be avoided by combining it with general anesthesia. However, in the available literature, there are no recommendations on the differentiated choice of the method of anesthesia for surgical interventions on the lower limbs in people of working age and the factors that influence this

Keywords: general anesthesia, regional anesthesia, injuries of the lower limbs, young people

How to Cite:

Georgiyants, M., Popsuishapka, O., Ryndenko, V., Kursov, S., Babalian, V., Bohuslavska, N. (2021). The problem of choosing anesthesia method for surgical interventions on the lower limbs in young patients. ScienceRise: Medical Science, 2 (41), 43-47. doi: http://doi.org/10.15587/25194798.2021.228780

(C) The Author(s) 2021

This is an open access article under the CC BY license (http://creativecommons.org/licenses/by/4.0).

\section{Intoduction}

Limb injuries occur in people of all ages. These injuries form a separate subgroup and are characterized by complexity and diversity; in particular, they are often high-energy lesions that are combined with other injuries [1]. Statistics show that $51 \%$ are domestic, $30 \%$ occur in the street, $10 \%$ are road injuries [2]. Isolated injuries of various segments of the lower limbs account for $54 \%$ of the total [3].

The frequency of limb fractures in the population is marked by bimodality: an increased frequency between children and adolescents and the elderly. Injuries of the intermediate age group are given relatively little attention [4], but $80 \%$ of the injured are people of working age from 20 to 59 years. Injuries in people of working age are an urgent problem, because mostly such patients have to stop working for a while, which turns this problem from a purely medical to social [5].

Lower limbs injuries differ in the course of the disease caused by the area of injury, the presence / absence of damage to nerves and blood vessels, and so on.
But it is necessary to note some pathogenetic signs that require simultaneous correction of traumatologists and anesthesiologists. First of all, such patients have a pronounced pain syndrome, caused, on the one hand, by direct damage to bones, nerves and surrounding tissues, on the other - local circulatory disorders and edema [6]. At the same time, infectious complications can develop due to ischemia in the area of surgery. The prolonged immobilization causes deterioration of venous outflow and the development of thromboembolic complications [7].

Surgery alters the homeostatic balance and defense mechanisms in the body, causing certain reactions, the so-called "surgical stress". The main purpose of anesthesia is to protect the body from surgical aggression. The choice of anesthesia is an important issue because it must provide effective antinociceptive protection during surgery and create favorable conditions for rapid rehabilitation and activation of the patient in the postoperative period.

Currently, traumatology uses increasingly complex methods of surgical treatment of the lower limbs 
injuries, while requiring the improvement of methods of their anesthesia. There is a lack of unanimous recommendations for analgesia in patients with injuries of the lower limbs, in clinical practice, along with the methods of general anesthesia and regional anesthesia [8]. Determining the optimal method of anesthesia for a particular type of surgery given the advantages and disadvantages is an immediate task of modern anesthesia.

The aim of the research was to conduct a systematic analysis of current data in the scientific literature on the possibility of using anesthesia methods during surgery for injuries of the lower limbs in people of working age.

\section{Materials and methods}

A search for scientific sources was carried out in the scientometric databases Scopus and Web of Science, Google Scholar, archives of journals using the keywords "general anesthesia", "regional anesthesia", "injuries of the lower limbs", "young people", "general anesthesia". The search depth was 8 years.

\section{Research results and discussion}

Nowadays, quite often techniques of general anesthesia are used in the case of the lower limbs injuries. It is known that in some countries, for example, the United States, general anesthesia is mainly used [9], while in domestic practice, regional methods of analgesia predominate [10]. General anesthesia is used mostly in case of impossibility of regional anesthesia due to contraindications and reluctance of the patient [11]. Thus, the researchers note that the reason for the refusal of $24.1 \%$ of patients, mostly females, with injuries of the lower limbs from regional anesthesia was a reluctance to be conscious during surgery [12]. Despite the lack of statistics on patients of working age, it can be assumed that some patients with labile psyche are likely to prefer a combination of regional and general anesthesia or general anesthesia.

General anesthesia is a traditional method of analgesia and in the case of surgery on the lower limbs should be used in conjunction with muscle relaxation and artificial ventilation, due to the complexity and duration of surgeries and the need to maintain adequate gas exchange while monitoring vital functions [13]. Methods of general anesthesia have a wide range of action, good control and rapid recovery of consciousness after surgery. Drugs used in such conditions in modern domestic anesthesiology, propofol (for total intravenous anesthesia) and sevoflurane (for inhalation anesthesia) are characterized by low toxicity and good tolerability [14]. However, the lack of general anesthesia is also known, which consists in the absence of complete blockade of peripheral nerve impulses, which causes the development of significant plastic changes in the central nervous system and the probable development of hyperalgesia. This can cause varying degrees of metabolic and hemodynamic reactions of the body [15]. To overcome such adverse effects resort to multimodal anesthesia, drugs of different groups, given their impact on the nociceptive system at different levels are used when in the process of analgesia [16].

According to the literature data, the following methods of regional anesthesia are increasingly used for injuries of the lower limbs: neuroaxial methods (subarachnoid, epidural, combined spinal-epidural) and various variants of nerve blocks (proximal and distal blockades) [17]. At the same time, neurostimulation and ultrasound navigation are increasingly used to identify nerve structures in modern clinical practice.

The advantages of regional methods of anesthesia over general anesthesia are the ability to locally block nociceptive stimulation in the area of injury and surgery, no complications from the pulmonary system, improved microcirculation and hemostasis, control of pain sensitivity in the perioperative period which promote early activity of patients [18].

The comparison shows certain advantages of neuroaxial methods of anesthesia over nerve blocks due to the simplicity and speed of conduction, reliability of anesthesia and the absence of the need for additional equipment. First of all, this applies to subarachnoid anesthesia which is technically easier to perform and master by specialists [19]. However, both methods are able to provide adequate analgesia of both limbs, which makes them the method of choice in surgeries in case of bilateral injuries of the lower limbs.

Neuroaxial methods of anesthesia have certain disadvantages: the likelihood of developing mostly cardiovascular complications (hypotension and bradycardia) due to high sympathetic block; nausea and vomiting due to the effects of anesthesia and hemodynamic fluctuations in the sympathetic block [20]. Along with this significant disadvantage of subarachnoid anesthesia, there is a post-puncture headache, which is most often complained of by patients aged $30-50$, that is a group of people of working age [21]. The literature discusses the causes, mechanisms, prevention and treatment of this complication of subarachnoid anesthesia [22].

Despite the shortcomings, in modern anesthesiological practice, regional anesthesia in the form of peripheral nerve blocks is becoming increasingly popular due to the lack of systemic effects on vital functions, effective analgesia in the perioperative period, the possibility of unilateral analgesia against neuroaxial techniques and economic component [23].

The most important question that arises in front of the anesthesiologist in the process of planning peripheral nerve blocks is to determine the location of the puncture, the method of identification of nerve structures and the choice of local anesthetic [24]. The most common nerve blocks used for anesthesia of lower limbs surgery in traumatology are lumbar, femoral, and sciatic nerve blockades [25]. During operations on the hip joint, blockade of the lumbar plexus is mainly used, in case of hip fractures, arthroscopy of the knee joint and other interventions - blockade of the femoral nerve [26]. Modifications of sciatic nerve blockade in combination with lumbar block or femoral nerve block create the possibility of analgesia during surgery in all parts of the lower limbs, and in isolation provide analgesia of the shin and foot [27].

Appropriate equipment and techniques is the key to safe and effective regional anesthesia. At the same time, the introduction of ultrasound (US) navigation has significantly increased the safety and effectiveness of anesthesia. However, not every domestic hospital has 
such equipment and trained specialists. Carrying out "blind" blockades significantly increases the failure rate during anesthesia. In addition, according to the latest information, neurostimulation, which was assumed to be the "golden standard" in the past, is not able to ensure an adequate level of nerve block [28]. Currently, ultrasound navigation allows the anesthesiologist to accurately position the needle and monitor the distribution of local anesthetic in the perineural area [29]. A significant advantage of ultrasound navigation is the ability to directly visualize other anatomical structures (vessels, muscles, bones), which facilitates the search for the nerve and allows you to avoid side effects and painful muscle contractions as in neurostimulation. At the same time, other advantages are the reduction of the dose of local anesthetic with increasing quality and duration of blockade [30]. Thus, ultrasound navigation helps to increase safety which is an important effect of anesthesia in modern medicine.

Attention should also be paid to local anesthetics used for regional anesthesia. These are mostly amide group drugs, as they cause allergic reactions to a much lesser extent [31]. Due to the mechanism of action aimed at blocking sodium channels, there is a cessation of nerve impulses in a certain area of the body. Lidocaine, bupivacaine, and ropivacaine are most commonly used for regional anesthesia [32]. The advantages and disadvantages of these drugs in the case of regional anesthesia are widely discussed in the literature. Researchers believe that the neurotoxicity of lidocaine limits its use in the case of subarachnoid anesthesia, but this disadvantage can be eliminated by reducing the dose of the drug through the use of ultrasound navigation [33]. Anesthesiologists use caution with bupivacaine, the selective cardiotoxicity of which may be caused by systemic action during intravascular administration due to its slow dissociation with sodium channels (the conduction system of the heart) [34]. Therefore, safer drugs levobupivacaine and ropivacaine have been developed, which in the future should become the drugs of choice in the case of anesthesia conduction [35].

Recently, when choosing a method of anesthesia for surgery, experts are increasingly paying attention to its effect on higher nervous functions. Regional anesthesia can prevent postoperative cognitive dysfunction in three ways: first, it provides complete analgesia, thus reducing the impact of pain on cognitive function; secondly, reduces the use of certain drugs, in particular, opioid analgesics, sedatives that can cause cognitive disorders; third, it reduces inflammatory and post-operative stress responses that are directly related to cognitive impairment [36]. Nevertheless, practical guidelines on perioperative brain health published in 2018 concluded that there was insufficient evidence to recommend the use of regional anesthesia instead of general anesthesia in terms of reducing the incidence of postoperative cognitive dysfunction [37].

Thus, it is still unclear whether anesthesia itself, or other surgical factors, or patient factors cause cognitive impairment. Studies that assess the risk profile of different methods of anesthesia are ambiguous, and there is no convincing evidence that one method is better than another. Discussions on this issue emphasize the need for further high-quality research.

\section{Conclusions}

The problem of choosing the method of analgesia during trauma surgery in people of working age has no definitive solution. Improvements in the methods of general anesthesia, the relative simplicity of its implementation, the rapid achievement of the patient's readiness for surgery against regional anesthesia maintain the widespread use of this type of anesthesia. In general, both general and regional anesthesia can be used, given their benefits and the potential for complications in each case. However, attitudes towards the safety of general anesthesia have changed in the last decade. Regional anesthesia in the treatment of pathology of the lower limbs remains the cornerstone of anesthesiology in traumatology practice. An important component of the use of local anesthesia is its specific effects, which go beyond anesthesia, providing blood conservation, regional muscle relaxation and improving microcirculation. The use of ultrasound navigation and modern local anesthetics in the minimum sufficient amount makes conduction anesthesia more effective and safer. Given the main disadvantages of regional (preservation of consciousness during surgery) and general anesthesia (insufficient analgesia in the lower segments of the pain impulse), this problem can be solved through a combination of these methods. In our opinion, the combination of regional (conductive) anesthesia with intravenous sedation with propofol has the least effect on vital functions of the body. However, there is a lack of information in the available literature on the clinical efficacy of this method of anesthesia compared to isolated regional anesthesia. It should be noted that there is no recommendation for differentiated choice of anesthesia in the case of the lower limbs surgery in people of working age and the factors that affect it. In our view, the factors that determine the differentiated choice of analgesia are the area of traumatic injury, the duration of the planned intervention, as well as the psychological state of the patient.

\section{Conflicts of interest}

The authors declare that they have no conflicts of interest.

\section{References}

1. Goudie, E. B., Duckworth, A. D., White, T. O. (2017). Hip fractures in young adults. Orthopaedics and Trauma, 31 (2), 76-85. doi: http://doi.org/10.1016/j.mporth.2016.10.004

2. Vyshlova, I. A., Karpov, S. M., Starodubtsev, A. I. (2016). Neuroimmunological mechanisms of chronic pain syndrome. Neurology, Neuropsychiatry, Psychosomatics, 8 (2), 113-116. doi: http://doi.org/10.14412/2074-2711-2016-2-113-116

3. Shostak, N. A., Pravdyuk, N. G. (2016). Pain syndrome: some diagnostic aspects. The Clinician, 10 (1), 10-11.

4. Farr, J. N., Melton, L. J., Achenbach, S. J., Atkinson, E. J., Khosla, S., Amin, S. (2017). Fracture Incidence and Characteristics in Young Adults Aged 18 to 49 Years: A Population-Based Study. Journal of Bone and Mineral Research, 32 (12), $2347-2354$. doi: http://doi.org/10.1002/jbmr.3228 
5. Grygorieva, N. V., Vlasenko, R. O. (2017). Epidemiology and risk factors of lower limb fractures (literature review). Pain. Joints. Spine, 7 (3), 127-138. doi: http://doi.org/10.22141/2224-1507.7.3.2017.116868

6. Sumitani, M., Yasunaga, H., Uchida, K., Horiguchi, H., Nakamura, M., Ohe, K. et. al. (2013). Perioperative factors affecting the occurrence of acute complex regional pain syndrome following limb bone fracture surgery: data from the Japanese Diagnosis Procedure Combination database. Rheumatology, 53 (7), 1186-1193. doi: http://doi.org/10.1093/rheumatology/ket431

7. Tarbiat, M., Majidi, M., Manouchehrian, N. (2019). Frequent Spinal Anesthesia in a Patient with Traumatic Lower Extremity Injury: A Case Report. Anesthesiology and pain medicine, 9 (2), e88595. doi: http://doi.org/10.5812/aapm.88595

8. Povoroznyuk, V. V., Grygorieva, N. V., Korzh, M. O., Strafun, S. S., Vaida, V. M., Klymovytsky, F. V. et. al. (2016). Epidemiology of the proximal femur fractures in ukraine: results of stop-study (system of registration of osteoporotic fractures in Ukrainian population). Trauma, 17 (5), 14-20. doi: http://doi.org/10.22141/1608-1706.5.17.2016.83870

9. Tsuda, T. (2017). Epidemiology of fragility fractures and fall prevention in the elderly: a systematic review of the literature. Current Orthopaedic Practice, 28 (6), 580-585. doi: http://doi.org/10.1097/bco.0000000000000563

10. Chaplynskyi, R. P., Perepelytsia, Ye. Ye., Berezka, M. I., Hariachy, Ye. V., Lytovchenko, V. O. (2017). Regional anesthesia with prolonged analgesia in treatment of multiple fractures of limbs. International Medical Journal, 1, 89-92.

11. Beerekamp, M. S. H., de Muinck Keizer, R. J. O., Schep, N. W. L., Ubbink, D. T., Panneman, M. J. M., Goslings, J. C. (2017). Epidemiology of extremity fractures in the Netherlands. Injury, 48 (7), 1355-1362. doi: http://doi.org/10.1016/j.injury. 2017.04.047

12. Cummings, S. R., Melton, L. J. (2002). Epidemiology and outcomes of osteoporotic fractures. The Lancet, 359 (9319), 1761-1767. doi: http://doi.org/10.1016/s0140-6736(02)08657-9

13. Ovechkin, A. M., Politov, M. E., Panov, N. V. (2017). Acute and chronic pain syndrome after total hip and knee replacement. Anesthesiology and Intensive Care, 63 (3), 224-230.

14. Pisarev, V. V., L’Vov, S. E., Vasin, I. V., Tikhomolova, E. V. (2012). Regional hemodynamics in different types of surgical treatment of diaphyseal fractures of the shin bone. Traumatology and Orthopedics of Russia, 1, 36-42. doi: http://doi.org/10.21823/2311-2905-2012-0-1-36-43

15. Bohuslavska, N. M., Heorhiiants, M. A. (2015). Choice of method of anesthesiological support of traumatological surgeries in young patients. ScienceRise, 7 (4 (12)), 28-35. doi: http://doi.org/10.15587/2313-8416.2015.47374

16. Kalashnykov, O., Stavynskyi, Y., Vdovichenko, K., Kalashnykov, A. (2019). Efficiency of multimodal analgesia in orthopedics and traumatology. Pain Medicine, 4 (3), 57-62. doi: http://doi.org/10.31636/pmjua.v4i3.3

17. Khvysiuk, O. M., Fesenko, V. S., Zavelia, M. I., Khvysiuk, O. M. (2006). Anesthesia in orthopedics and traumatology. Kharkiv, 416.

18. Voysekhovskiy, D. V., Averyanov, D. A., Schegolev, A. V., Svistov, D. V. (2018). Effect of deep anesthesia on development of post-operative cognitive dysfunction. Messenger of Anesthesiology and Resuscitation, 15 (1), 5-9. doi: http://doi.org/10.21292/2078-5658-2018-15-1-5-9 tricht, 124.

19. Bouman, E. A. (2015). Risks and benefits of regional anesthesia in the perioperative setting. Universitaire Pers Maas-

20. Matot, I. (2018). Anesthetics and Trauma: A Complex Interaction. Anesthesia and analgesia, 127 (5), e84-e85. doi: http://doi.org/10.1213/ane.0000000000003727

21. Kwak, K.-H. (2017). Postdural puncture headache. Korean Journal of Anesthesiology, 70 (2), 136-143. doi: http://doi.org/10.4097 /kjae.2017. 70.2.136

22. Yüksek, A., Miniksar, Ö. H., Honca, M., Öz, H. (2020). Incidence and Causes of Failed Spinal Anesthesia. Dubai Medical Journal, 3 (2), 50-54. doi: http://doi.org/10.1159/000508837

23. Bomberg, H., Wetjen, L., Wagenpfeil, S., Schöpe, J., Kessler, P., Wulf, H. et. al. (2018). Risks and Benefits of Ultrasound, Nerve Stimulation, and Their Combination for Guiding Peripheral Nerve Blocks: A Retrospective Registry Analysis. Anesthesia and analgesia, 127 (4), 1035-1043. doi: http://doi.org/10.1213/ane.0000000000003480

24. Rowley, P., Boncyk, C., Gaskell, A., Absalom, A., Bonhomme, V., Coburn, M. et. al. (2017). What do people expect of general anaesthesia? British Journal of Anaesthesia, 118 (4), 486-488. doi: http://doi.org/10.1093/bja/aex040

25. Musaeva, T. S., Dashevsky, S. P., Trembach, N. V. (2017). Comparative analysis of combined anesthesia course based on sevoflurane or propofol in old age patients with different levels of wakefulness. Russian journal of anaesthesiology and reanimatology, 62 (5), 363-368.

26. Sikorski, R. A., Koerner, A. K., Fouche-Weber, L. Y., Galvagno, S. M. (2014). Choice of General Anesthetics for Trauma Patients. Current Anesthesiology Reports, 4 (3), 225-232. doi: http://doi.org/10.1007/s40140-014-0066-5

27. Hlumcher, F. S. (2013). Induction and maintenance of inhalation anesthesia (VIMA) with sevoflurane in adult patients requiring surgical placement: assessment of the quality of anesthesia by anesthesiologists and patients. Pain, analgesia and intensive care, $4,12-26$.

28. Guimarães, J. F., Angonese, C. F., Gomes, R. K., Junior, V. M., Farias, C. (2017). Anesthesia for lower extremity vascular bypass with peripheral nerve block. Revista brasileira de anestesiologia, 67 (6), 626-631. doi: http://doi.org/10.1016/j.bjan. 2015.12.003

29. Lewis, S. R., Price, A., Walker, K. J., McGrattan, K., Smith, A. F. (2015). Ultrasound guidance for upper and lower limb blocks. The Cochrane database of systematic reviews, 2015 (9), CD006459. doi: http://doi.org/10.1002/14651858.cd006459.pub3

30. Guay, J., Suresh, S., Kopp, S. (2019). The use of ultrasound guidance for perioperative neuraxial and peripheral nerve blocks in children. The Cochrane database of systematic reviews, 2 (2), CD011436. doi: http://doi.org/10.1002/14651858.cd011436.pub3

31. Lončarić-Katušin, M., Mišković, P., Lavrnja-Skolan, V., Katušin, J., Bakota, B., Žunić, J. (2017). General versus spinal anaesthesia in proximal femoral fracture surgery - treatment outcomes. Injury, 48, S51-S55. doi: http://doi.org/10.1016/s00201383(17)30740-4

32. Kuchyn, Yu. L., Pylypenko, M. M., Nalapko, Yu. I., Krehh, R. (2016). Local anesthetics: a modern view. Pain Medicine, 3, 17-18.

33. Kim, D. D., Asif, A., Kataria, S. (2016). Presentation of Neurolytic Effect of $10 \%$ Lidocaine after Perineural Ultrasound Guided Injection of a Canine Sciatic Nerve: A Pilot Study. The Korean journal of pain, 29 (3), 158-163. doi: http://doi.org/10.3344/kjp.2016.29.3.158

34. Nociti, J. R. (2017). Ropivacaine: the newest anesthetic agent celebrates 20 years. Revista Dor, 18 (4). doi: http://doi.org/10.5935/1806-0013.20170117 
35. Singh, R., Maheshwari, V., Rasheed, M., Choubey, S., Sarkar, A. (2016). Comparison of ropivacaine with levobupivacaine under epidural anesthesia in the lower limb orthopedic surgeries: A randomized study. Anesthesia: Essays and Researches, 10 (3), 624-630. doi: http://doi.org/10.4103/0259-1162.191119

36. Andreae, M. H., Atchabahian, A., McCrillis, A. M., Chao, J. Y., Suzuki, S., Shinnar, S., Hall, C. B., Lipton, R. B. (2016). Regional versus general anaesthesia for improved cognitive function after procedures other than cardiac surgery or neurosurgery in adult and paediatric patients. The Cochrane database of systematic reviews, 2016 (6), CD008737. doi: http://doi.org/10.1002/14651858.cd008737.pub2

37. Berger, M., Schenning, K. J., Brown, C. H., Deiner, S. G., Whittington, R. A., Eckenhoff, R. G. (2018). Best Practices for Postoperative Brain Health: Recommendations From the Fifth International Perioperative Neurotoxicity Working Group. Anesthesia and analgesia, 127 (6), 1406-1413. doi: http://doi.org/10.1213/ane.0000000000003841

Received date 16.12.2020

Accepted date 04.01.2021

Published date 31.03.2021

Marine Georgiyants, MD, PhD, Professor, Department of Anesthesiology, Pediatric Anesthesiology and Intensive Care, Kharkiv Medical Academy of Postgraduate Education, Amosova str., 58, Kharkiv, Ukraine, 61176

E-mail: vice-rector_nauka@med.edu.ua

Olexii Popsuishapka, MD, PhD, Professor, Department of Traumatology and Orthopedics, Kharkiv Medical Academy of Postgraduate Education, Amosova str., 58, Kharkiv, Ukraine, 61176

E-mail: alexeycorn@gmail.com

Victor Ryndenko, MD, PhD, Professor, Head of Department, Department of Traumatology, Anaesthesiology and Military, Kharkiv Medical Academy of Postgraduate Education, Amosova str., 58, Kharkiv, Ukraine, 61176 E-mail: vertebrology@med.edu.ua

Sergiy Kursov, MD, PhD, Professor, Department of Emergency Medicine and Disaster Medicine, Kharkiv Medical Academy of Postgraduate Education, Amosova str., 58, Kharkiv, Ukraine, 61176

E-mail: s.v.kursov@mail.ru

Volodymyr Babalian, PhD, Associate Professor, Department of Traumatology, Anaesthesiology and Military, Kharkiv Medical Academy of Postgraduate Education, Amosova str., 58, Kharkiv, Ukraine, 61176 E-mail: babalyanvladimir@gmail.com

Nataliia Bohuslavska, PhD, Assistant, Department of Anesthesiology, Pediatric Anesthesiology and Intensive Care, Kharkiv Medical Academy of Postgraduate Education, Amosova str., 58, Kharkiv, Ukraine, 61176 E-mail: nata-anest-78@ukr.net 